\title{
THE IMPACT OF KNOWLEDGE PROCESS CAPABILITIES ON INNOVATION PERFORMANCE: AN EMPIRICAL RESEARCH ON R\&D CENTERS
}

DOI: 10.17261/Pressacademia.2021.1473

RJBM- V.8-ISS.4-2021(7)-p.291-299

Esin Sayin Yesildal ${ }^{1}$, Rifat Kamasak ${ }^{2}$

${ }^{1}$ KOSGEB, Tekirdag Headquarter, Tekirdag, Turkey. esin.sayin@kosgeb.gov.tr, ORCID: 0000-0002-7155-2879

${ }^{2}$ Yeditepe University, Faculty of Economics and Administrative Sciences, Istanbul, Turkey. rifat.kamasak@yeditepe.edu.tr, ORCID: 0000-0001-8768-3569

\begin{tabular}{l}
\hline Date Received: October 11, $2021 \quad$ Date Accepted: December 22, $2021 \quad$ open OAccEss \\
\hline To cite this document \\
Yesildal E., Kamasak, R. (2021). The impact of knowledge process capabilities on innovation performance: an empirical research on R\&D \\
centers. Research Journal of Business and Management (RJBM), 8(4), 291-299. \\
Permanent link to this document: http://doi.org/10.17261/Pressacademia.2021.1473 \\
Copyright: Published by PressAcademia and limited licensed re-use rights only.
\end{tabular}

\section{ABSTRACT}

Purpose- The purpose of this research is to investigate the impact of knowledge process capabilities on firms' innovation performance through an empirical study that was carried out on a sample of firms' R\&D centers. It is expected that the findings will offer practical implications to firms as well providing valuable insights to the academic literature.

Methodology- The data which were collected by a survey from officially approved 145 R\&D centers of firms which operate across various industries in Turkey, were analyzed. The explaratory factor analysis yielded two factors that were knowledge absorption and knowledge implementation. The two factors were entered to the model and the impact of knowledge process capabilities on innovation performance was investigated by multiple regression analysis.

Findings- Knowledge process capabilities are highly associated with innovation performance and knowledge processing is suggested as a predictor of innovation. In line, the results revealed a significant and positive relationship between knowledge process capabilities and firms' innovation performance. Namely, firms which developed better capabilities in processing knowledge could innovate better.

Conclusion- In order to increase innovativeness and and innovation-related performance of firms, several tools and mechanisms such as HR policies, leadership styles, flexibility in organizational architecturing, teamwork and continuous learning and training activities were suggested. Moreover, some improvements on the knowledge-related capabilities such as knowledge creation, sharing and implementation were advised.

Keywords: Knowledge process capabilities, dynamic capabilities, innovation performance, R\&D centers, regression analysis.

JEL Codes: L25, M19, O31, O32

\section{BiLGi iŞLEME YETENEKLERININ INOVASYON PERFORMANSINA ETKISI: AR-GE MERKEZLERI ÜZERINE AMPIRIK BIR ARAŞTIRMA}

\section{ÖZET}

Amaç- Bu araştırmanın amacı Ar-Ge merkezleri özelinde işletmelerin bilgi işleme yetenekleri ile inovasyon performansı arasındaki ilişkinin ampirik olarak incelenmesidir. Araştırma bulgularının işletmelerde inovasyon performansının arttııılmasına yönelik pratik öneriler sunması yanında literatüre de katkı sağlaması beklenmektedir.

Metodoloji- Türkiye'de Sanayi ve Teknoloji Bakanlı̆̆ı tarafından onaylanmış 145 Ar-Ge merkezi yöneticisi tarafından yanıtlanan anket yöntemi ile veri toplanmıştır. Veri seti önce açıklayıcı faktör analizine tabi tutulmuş ve bağımsız değişken bilgi işleme yetenekleri, bilgiyi absorbe edebilme ve bilgiyi uygulayabilme olarak adlandırılan iki faktör altında toplanmışır. Bu iki faktör modele dahil edilirken, değişkenler arasındaki ilişkinin değerlendirilmesi için regresyon analizleri kullanılmışıır.

Bulgular- Bilgi işleme yeteneklerinin inovasyon performansının öncülleri arasında yer aldığı iddia edilmektedir. Bu doğrultuda işletmelerin bilgi işleme yetenekleri ile inovasyon performansı arasında anlamlı ve pozitif ilişkilerin varlığı tespit edilmiştir. Kısacası, bilgi işleme yeteneklerini daha fazla geliştiren işletmelerin daha yüksek inovasyon performansı yarattığı ortaya çıkmıştır.

Sonuç- İnovasyon performansının artııılabilmesi için Ar-Ge merkezlerinin insan kaynakları politikaları, bilgi odaklı yönetici-lider tarzları, organizasyonel yapılarda esneklik, takım çalışması ve sürekli öğrenme gibi araç ve mekanizmalarla desteklenmesi önerilmektedir. Ayrıca, işletmelerin yaratııı ve yenilikçi performanslarını üst düzeye çıkarabilmelerinin, kolay ve verimli bilgi edinme, aktarma ve uygulamayı kolaylaştıran sağlam bilgi sistemlerine bağıı olduğu ifade edilmektedir.

Anahtar Kelimeler: Bilgi işleme yetenekleri, dinamik yetenekler, inovasyon performansı, Ar-Ge merkezleri, regresyon analizi. JEL Kodları: L25, M19, 031, 032 


\section{GiRiş}

İşletmeler rekabet avantajlarını, özgün kaynak ve kabiliyetlere sahip olma ve bunları kullanma yetileri sayesinde koruyabilmektedirler. Bu amaca ulaşmada dinamik yetenekler (Teece vd., 1997; Kamaşak ve Yozgat, 2013; Teece, 2018; Kamaşak ve Cansever, 2019) en önemli stratejik perspektiflerden birisi olarak karşımıza çıkmaktadır. İşletmelerin durağan kaynak yapısını çevresel etkiler ile tüketici ve pazar gereksinimleri doğrultusunda yenileyen, genişleten ya da yeniden yapılandıran beceriler olarak tanımlanan dinamik yetenekler (Teece vd., 1997; Zott, 2003; Kamaşak, 2011, 2014, 2015a; Kamaşak ve Yavuz, 2016) arasında bilgi işleme yeteneklerinin bulunduğu ifade edilmektedir (Yayavaram ve Chen 2015; Kamaşak, 2017; Kamaşak vd., 2017a; Joshi vd., 2021). Kısaca, işletmelerin mevcut kaynaklardan yararlanma ve yeni kapasiteler oluşturma süreçlerinde bilgiyi temel alarak performanslarını yükseltmeleri ve rekabet avantajı oluşturmaları hedeflenmektedir. İ̧̧letmeler çevredeki değişiklikleri gözlemleyerek yeni fırsatlardan yararlanmak için doğru bilgiyi toplamalı, onu kurumsal bilgi temellerine entegre etmeli ve bu çerçevede hareket edebilmek için bilgi işleme süreçlerini kullanmalıdırlar (Gold vd., 2001; Kamaşak vd., 2016a; Monteiro ve Birkinshaw, 2017).

Bu doğrultuda inovasyon üzerine yapılan tartışmaların çoğu, özellikle de kuruluşu yeni olmayan KOBi'lere ve büyük işletmelere, yeni girdileri özümseme ve bunları uygun yeteneklere dönüştürme konusunda yardımcı olabilecek bilgi akışı türlerinin araştırılmasına odaklanmıştır (Parrilli ve Elola, 2012; Braojos vd., 2020). Bununla birlikte, bilgi işleme yeteneklerinin örgütsel performans üzerindeki etkisini açıklamak için halen az sayıda ampirik çalışmanın varlığına rastlanmaktadır. Bilgi ile yenilik arasındaki ilişkinin varlığı dikkate alındığında bilgi işleme yeteneği (BiY) ile özellikle inovasyon performans çıktılarını inceleyen araştırmaların ise daha da sınırlı sayıda olduğu göze çarpmaktadır (Easterby-Smith vd., 1999; Easterby-Smith ve Lyles, 2003; Jantunen, 2005; Kamaşak vd., 2017a; Gonzalez, 2021). Bu çalışmanın amacl, Ar-Ge merkezleri özelinde işletmelerin bilgi işleme yeteneklerinin inovasyon performanslarına olan etkisini ampirik olarak araştırmaktır. Araştırma bulgularının işletmelerde inovasyon performansının arttırılmasına yönelik literatüre katkı sağlaması beklenmektedir.

Çalışmanın ilk bölümünde bilgi işleme yeteneği ve inovasyon performansı literatürüne değinilecek ve temel çalışmalar incelenecektir. İkinci bölümde ülkemizde Ar-Ge merkezlerinin oluşumu ve bu özelde yapılan araştırma açıklanacaktır. Son bölümünde ise araştırma bulguları özetlenerek sonuç ve önerilere yer verilecektir.

\section{LITERATÜR TARAMASI}

\subsection{Bilgi Işleme Yetenekleri}

Bilgi ve bilgiye dayalı süreçler, organizasyonların gelişimi için merkezi konumlardadırlar. Polanyi (1962) ve Nonaka'nın (1994) çalışmalarına dayanan bilgi sınıflandırmaları, örgütsel bilginin örtük ve açık olmak üzere iki uzantısını açıklamaktadır; Polanyi'ye (1966) göre, açık bilgi sistematik ve biçimsel bir dilde düzenlenebilen bir bilgidir; örtük bilgi ise sözlü olmayan, eklemlenmemiş ve içgüdüseldir. Açık bilgiyi geliştirecek ve netleştirecek yapının belirlenmesi için gerekli olan arka plan, örtük bilgi tarafından oluşturulur (Polanyi ve Prosch, 1975). Nonaka (1994), örtük bilginin bağlama özgü, kişisel olarak sınırlı, ifade edilmesi zor ve eyleme derinden kök saldığını, dolayısıyla hem bilişsel hem de teknik unsurlardan oluştuğunu öne sürmektedir. Alavi ve arkadaşları (2001) bilişsel öğenin bireyin bakış açıları, paradigmalar, inançlar ve zihinsel haritalar dahil olmak üzere zihinsel modellerine atıfta bulunduğuna, teknik bileşenin ise somut bilgi, beceri ve neyi nasıl yapabileceğini bilmekten oluştuğunu belirtmektedir. İşletmenin genel işleyişi için gerekli olan ve genelde insanların zihninde bulunan örtük bilgiyi kaybetmemek, korumak ve sürdürmek, bilginin elde tutulması olarak ifade edilebilir (Marsh ve Stock, 2006). Bilgiyi elde tutma süreçleri, işletmelerin organizasyonel kalıpları koruduğu ve geliştirdiği süreçlerdir. Amaç, bilgiyi zaman içinde yararlı ve istikrarlı tutan organizasyonel kalıpları geliştirmektir (Kraaijenbrink, 2012).

Bilgiye ulaşmanın ve elde tutmanın (korumanın) haricinde bilginin işletme içerisinde paylaşımı ve paydaşlara aktarımı da özellikle yenilikçi ve yaratıcı çıktılar açısından hayati önem taşımaktadır (Kamaşak ve Bulutlar, 2010; Acharya vd., 2022). Bilgi; bireyler, gruplar, departmanlar ve bölümler dahil olmak üzere organizasyonun çeşitli seviyelerinde resmi ve gayri resmi kanallar aracılı̆ıyla aktarılabilir. Bilgi aktarımı olmadan, mevcut bilginin yaratıcı performans üzerindeki etkisi en aza indirilecektir. Bir işletmede bilginin entegrasyonu ve güvenilirliği artırmak, eski bilgileri değiştirmek, karmaşıklığı azaltmak, yani bilgi sinerjisini tamamen optimize edebilmek için mevcut bilgiyi organize etme, yeniden yapılandırma ve yorumlama gerekliliği ortaya çıkmaktadır (Wu ve Chen, 2014). Dolayısıyla, işletmenin yenilik süreci, faydalı yeni bilgi entegrasyonlarını bulmak için yoğun bir kaynak araştırmasını ve etkin bilgi edinim ve kullanım süreçlerine başvurulmasını zorunlu kılmaktadır. Araştırmacılar, bu bilgi sürecinin yönetimi için birçok önemli faktörün farkına varmışlardır: yakalama, aktarma ve kullanma (Long, 1997); birleştirme, bütünleştirme ve kullanma (Teece, 1998); oluşturma, aktarma, depolama ve uygulama (Alavi ve Leidner, 2001). Genel olarak incelendiğinde, bilgi yönetim sürecinin bilgiyi yaratma, aktarma, entegrasyon ve uygulama şeklinde gruplandırıldı̆̆ı görülmektedir (Kamaşak vd., 2017a). Kısacası, işletmelerin bilgiyi verimli bir şekilde bütünleştirmek ve kullanmak için zorluklarla karşılaştı̆̆ kabul edilmekte ve işletmelerin organizasyonel sınırları boyunca bilgi alışverişinde bulunmaları tavsiye edilmektedir (Lee vd., 2017; Turulja ve Bajgoric, 2018).

Bu doğrultuda bilgi alışverişini sağlayan bilgi işleme yeteneği, organizasyonlarda bilgi kaynaklarının edinilmesi (ya da ortaya çıkartılması), paylaşılması, özümsenmesi ve uygulanması gibi süreçleri içermektedir (Alavi ve Leidner, 2001; Tanriverdi, 2005). 
Ancak bu süreçleri daha az zaman alıcı ve belirli hale getirme gerekliliğine rağmen, literatürde bilginin arama, bulma, düzenleme ve birleştirme dinamiklerinin tam olarak anlaşılmadığı ifade edilmekte ve bilginin etkinliğinin artırılabilmesi için bir takım dinamik mekanizmaların gerekliliği vurgulanmaktadır (Zander ve Kogut, 1995; Acharya vd., 2022). Literatürde (örn., Kogut, 2000; Tanriverdi, 2005; Kamaşak vd., 2016b; McDowell vd., 2018) sıklıkla dinamik ortamlarda faaliyet gösteren işletmelerin yaratıcı çıktılar üretebilmek için bilgi kaynaklarını sürekli olarak yenileme ve birleştirme zorunluluğu vurgulanırken, işletme çalışanlarının bilgi ve uzmanlı̆̆ından yararlanmak için de kaynakların bütünleştirilmesi, yeniden yapılandırılması, paylaşııması ve uygulanmasını öneminden bahsedilmektedir. Bu nedenle, değişen piyasa koşullarına yanıt vermek için yeni ürünlerin yaratılmasını sağlayan bir kapasite alt kümesi olan "dinamik yetenekleri" etkinleştirmek esastır (Savino vd., 2017; Chen vd., 2022).

Dinamik yeteneklerin, organizasyonlar içinde bilginin işlenmesi olarak tanımlanabilecek yollarla geliştiği düşünülür ve organizasyonlarda rekabet avantajı sağlamak için stratejik bir faktör olarak bilginin işlenmesi dikkate alınır (Grant, 1996; Zollo ve Winter, 2002; Zahra vd., 2007; Kamaşak, 2013; Mostafiz vd., 2021). Başka bir deyişle, dinamik yetenekler yaklaşımı, işletmenin uzun vadeli ve sürekli yenilenmesinin hem mevcut bilgi temelli yetkinliklerden yararlanmaya hem de yeni bilgi temelli yetkinlikler bulmasına bağlı olduğunu ileri sürer (Gibson ve Birkinshaw, 2004). Kısacası, bilgi yönetimi ya da bilgi işleme yeteneği, farklı bilgi türlerini sentezlemek ve yetenekler elde etmekten oluşan çeşitli öğrenme kabiliyetleri için bir araçtır (Ermine, 2018). Bireysel bilginin paylaşılması ve geliştirilmesi, yeni bilginin ürün ve hizmetlere entegrasyonu ve işletme genelinde anlayışın aktarılması gibi farklı prosedürleri içeren bilgi işlem yetenekleri ile inovasyon arasındaki ilişki bir sonraki bölümde açıklanmıştır.

\subsection{Bilgi İşleme Yetenekleri ve İnovasyon Performansı}

İnovasyon, yarattığı katma değer sayesinde işletmelerin üretkenliğini ve karlıı̆ı̆n artıran ve yeni pazarlara girişlerini kolaylaştıran bilgiye dayalı sürdürülebilir bir rekabet aracıdır (Pınar vd., 2010; Mol ve Birkinshaw, 2014; Kamaşak vd., 2016a; Cebeci ve Kamaşak, 2021). Bu doğrultuda inovasyon performansının büyük ölçüde işletmelerin bilgi edinme, üretme ve uygulama kapasitelerine bağı olduğu söylenebilir. Özellikle yeni bilginin edinilmesi, işletmelerin dış ortamdaki değişiklikleri kolayca fark etmelerini, hızlı yanıt vermelerini ve yardımcı dış teknolojileri belirleyebilmelerini sağlamaktadır. Yeni bilgi ediniminin bir diğer hayati katkısı da odak işletmelerin (focal companies) açıklığını geliştirmesi ve açık inovasyon çağında daha iyi inovasyon politikaları üretebilmeleri ve uygulamalarına yardımcı olmasıdır (Kang ve Kang, 2014; Kamaşak, 2015b; Henttonen ve Lehtimäki, 2017). Şüphesiz dünyadaki gelişen eğilimleri takip edebilme ve gizli pazarın gereksinimlerini belirleyebilme kapasitesi, bir işletmenin bilgi yönetimi rutinlerinde ve süreçlerinde ne kadar iyi olduğunu yansıtır. En küçük sinyalleri ve olasılıkları tespit etmeye yönelik organizasyonel yetenekler, uzun vadede esasen yenilikçi performansa ve rekabet gücüne katkıda bulunur (Jantunen, 2005; Teece, 2018). Muhtemel pazar gelişimleri ve tüketicilerin tercihlerinde meydana gelmesi beklenen değişimleri bilgi temelli kaynaklar ve bilgi süreçleri vasıtası ile önceden görebilmek işletmeyi rakiplerinden bir adım öne çıkartabilmektedir. Ancak, bu değişimlere cevap verebilecek yenilikçi ürün, hizmet, süreç ya da metotların sunulabilmesi, yeni bilginin işletme içi ya da dışından edinilmesinin yanında bu bilginin özümsenmesi, kurum kültürüne entegre edilmesi ve paydaşlar arasında paylaşılarak çeşitli uygulamalara konu olması ile gerçekleşebilmektedir (Wu ve Chen, 2014).

Bilgi işleme konusunda gelişmiş yeteneklere sahip işletmeler, kolay ulaşılamayan, stratejik olarak nitelendirilebilecek bilgi üretimi sayesinde pazar ihtiyaçlarını karşılayabilecek yenilikçi ürün ve hizmetleri rakiplerine oranla daha hızlı sunabilecek ve bu doğrultuda mevcut kaynaklarını da daha verimli kullanabilecektir (Jantunen, 2005; Lee vd., 2017). Böylece bilgi işletme yetenekleri, işletmelerin özellikle inovasyon için gerekli olan bilgi tabanlı kaynaklarını bir rekabet avantajı kaynağı haline getirmektedir. Akademik literatürde, bilgi işlem yetenekleri ile inovasyon performansı arasındaki ilişkiyi inceleyen bazı çalışmalar mevcuttur.

Jantunen'in (2005) yedi farklı endüstride faaliyet gösteren 217 Finlandiya firmasını kapsayan çok boyutlu, dinamik bir model kullanarak yaptığı ampirik araştırmasında, bilgi işleme yeteneklerinin işletmenin yalnızca bilgi envanterini değil, aynı zamanda yenilikçi performansın sürdürülebilmesi için bilgi akışını da desteklediği görülmüştür. Benzer bir araştırmada Berchicci (2013) 500'den az çalışanı olan İtalyan imalat firmalarını incelemiş ve araştırma sonuçlarına göre, Ar-Ge faaliyetlerinin ve bilgi edinmenin daha iyi yenilikçi performansa neden olduğu anlaşılmıştır. Bir diğer araştırmada Donate ve de Pablo (2015) inovasyon performansı ve bilgi işleme yetenekleri arasında pozitif bir ilişki olduğunu göstermiştir. Bilgi yaratma ve kullanmanın önemli ölçüde yenilik performansıyla ilişkili olduğu bulunurken, bilginin depolanması ve tahsisi ile yenilik performansı arasında anlamlı bir ilişki gözlenmemiştir. Kamaşak ve arkadaşları (2017a) tarafından İstanbul Sanayi Odası'na kayıtlı farklı endüstrilerde faal olan 236 işletmeyi içeren araştırma sonuçlarına göre bilgi işleme yetenekleri gelişmiş olan firmaların daha fazla patent ve tescilli marka yaratabildiği ve daha özgün ürün ve hizmet üretebildiği görülmüştür.

Bu bulgular çerçevesinde bilgi üretebilme, bütünleştirebilme ve etkin olarak kullanabilmeyi sağlayan bilgi işleme yeteneklerine sahip işletmelerin daha yenilikçi ve buna dayalı olarak daha uzun vadeli sürdürülebilir rekabet avantajına sahip olacakları söylenebilir. Bu doğrultuda araştırma hipotezi aşağıdaki şekilde oluşturulmuştur:

H1: Bilgi işleme yetenekleri ile inovasyon performansı arasında anlamlı pozitif bir ilişki vardır. 


\section{3. ÇALIŞMANIN YÖNTEMI}

$\mathrm{Bu}$ araştırmada, işletmelerin bilgi işleme yeteneklerinin inovasyon performansı üzerindeki etkisi araştırılmıştır. Ar-Ge merkezleri bulunan farklı endüstrilerde faaliyet gösteren işletmelerden toplanan verilerin analizi sonrasında elde edilen sonuçlar incelenmiştir.

\section{1. Örneklem}

Araştırmanın örneklemi, T.C. Sanayi ve Teknoloji Bakanlığı Ar-Ge Merkezi belgeli ve 30 Kasım 2021 itibari ile Ar-Ge Merkezi statüsü devam eden 1254 faal işletmeden oluşmaktadır. Ar-Ge Merkezleri, işletmelerin organizasyon yapısı içinde ayrı bir bölüm olarak örgütlenmiş, münhasıran yurtiçinde araştırma ve geliştirme faaliyetlerinde bulunan ve en az 15 tam zamanlı personel istihdam eden, yeterli Ar-Ge birikimi ve yeteneğine sahip, işletme ile aynı bina veya aynı yerleşke içerisinde yer alan birimlerdir (Sanayi Bakanlığı, 2021).

Araştırma için kullanılacak anketlerin çevrimiçi bağlantısı, araştırmanın amacını açıklayan ve yanıtlarının gizliliğini garanti eden bir ön yazı ile şirketlerin Ar-Ge departman yöneticilerine gönderilmiştir. Ardından, araştırmayı hatırlatmak ve anketin yanıtlanma oranını artırmak için telefon görüşmeleri gerçekleştirilmiştir. Bu şekilde toplam kullanılabilir 145 ankete geri dönüş alınmıştır. Böylece anketlere geri dönüş oranı yaklaşık \%12 olmuştur. Ankete katılan firmalardan bazılarının birden fazla ArGe merkezi bulunmaktadır. Örneğin, Vestel ve Aselsan şirketinin 6, Arçelik Grubu'nun ise 11 Ar-Ge merkezi bulunmaktadır. Bu şirketlerin oldukça benzer bir yönetim anlayışına sahip oldukları düşünüldüğü için grup şirketinden sadece 1 firma olacak şekilde anketler doldurtulmuştur. Araştırmaya katılan firmalara ait veriler Tablo 1'de gösterilmektedir.

Çalışmada yer alan firmaların ağılıklı olarak, \%31'inin gıda, \%24,8'inin ise tekstil sektörlerinde yer aldıkları görülmektedir. Bu oranları \%5,4'er ile plastik ve metal/alüminyum, \%4,2'şer ile makine, boya/kimya ve kâğıt/ambalaj, \%3,4'er ile otomotiv/yedek parça ve elektrik/elektronik, \%2,7 ile ilaç/sağ/ık ve \%11,3 ile diğer sektörler izlemektedir. Çalışan sayısına bakıldığında katılımcı firmaların \%28,2'sinin 10 ile 49 arası çalışana sahip küçük ölçekli işletmeler, \%38,6'sının 50 ile 249 arası çalışana sahip orta ölçekli işletmeler, $\% 33,2$ 'sinin ise 250 ve üzeri çalışana sahip büyük işletmelerden oluştuğu görülmektedir.

Tablo 1: Katılımcılara Ait Demografik Bilgiler

\begin{tabular}{|c|c|c|c|}
\hline Değişken & Kategori & Sayı & Oran (\%) \\
\hline \multirow{3}{*}{ Çalışan sayısı } & $10-49$ & 41 & 28,2 \\
\hline & $50-249$ & 56 & 38,6 \\
\hline & 250 ve üzeri & 48 & 33,2 \\
\hline \multirow{3}{*}{$\begin{array}{l}\text { Tercih edilen Ar-Ge } \\
\text { kaynak yöntemi }\end{array}$} & Çalışanlara eğitim verilmesi & 91 & 62,7 \\
\hline & Bilimsel ortaklarla iş birliği & 28 & 19,3 \\
\hline & Yeni işe alınanların fikirleri/Pazar araştırması sonuçları & 26 & 18,0 \\
\hline \multirow{11}{*}{ Sektör } & Gıda & 45 & 31 \\
\hline & Tekstil & 36 & 24,8 \\
\hline & Plastik & 8 & 5,4 \\
\hline & Metal/Alüminyum & 8 & 5,4 \\
\hline & Makine & 6 & 4,2 \\
\hline & Boya/Kimya & 6 & 4,2 \\
\hline & Kâğıt/Ambalaj & 6 & 4,2 \\
\hline & Otomotiv Yedek Parça & 5 & 3,4 \\
\hline & Elektrik/Elektronik & 5 & 3,4 \\
\hline & İlaç/Sağlık & 4 & 2,7 \\
\hline & Diğer & 16 & 11,3 \\
\hline \multicolumn{2}{|l|}{ Toplam } & 145 & 100 \\
\hline
\end{tabular}

Araştırmaya dahil olan işletmelerin \%62,7 ile Ar-Ge kaynağı olarak en çok çalışanların eğitilmesi yöntemini tercih ettiği gözlenmektedir. Bunu \%19,3 oranı ile bilimsel ortaklarla işbirliği ve \%18 ile yeni işe alınan çalışanların fikirleri ve yapılan pazar araştırması sonuçları izlemektedir. Bilimsel ortaklarla işbirliği süreci değerlendirildiğinde işletmelerin ortalama 5 yıldır ortak iş yapma kültürünü benimsediği ve toplam 400 proje yürüttükleri görülmektedir. Katılımcı işletmelerin oluşturduğu örneklemi biraz daha genel bir çerçeve ile incelediğimizde, son 3 yıl içinde işletmelerin toplam satışlarının ortalama \%20'sinin yeni veya geliştirilmiş ürünlerden geldiği görülmektedir. Benzer şekilde işletmelerin projelerinde en çok destek aldıkları ya da işbirliği yaptıkları kurumların sırasıyla TTGV, Santez, TÜBITAK ve KOSGEB olduğu anlaşılmaktadır.

\section{2. Ölçüm Araçları, Güvenilirlik ve Geçerlilik}

Veri toplama aracı olarak anket yöntemi kullanılmıştır. Bağımsız değişken olan bilgi işleme yetenekleri için uygulanan 12 soruluk ölçek Alavi ve Leidner (2001), Gold ve arkadaşları (2001), Tanriverdi (2005) ile Wu ve Chen'in (2014) çalışmalarından 
uyarlanmıştır. Farklı ülkelerde değişik çalışmalarda kullanılan ölçek, ülkemizde de Kamaşak ve arkadaşları (2017a) tarafından geçerlilik ve güvenilirlik analizlerine tabi tutulmuş ve bir uygulama gerçekleştirilmiştir. Bağımlı değişken olan inovasyon performansı ise Jansen ve arkadaşları (2009) ile Wei ve arkadaşlarının (2014) ölçeklerinden alınan ve yeni ürün sayısı, pazara sunulan ürünlerin pazara yayılma hızı, yeni ürünlerin pazardaki başarısı ve geliştirilen yeni yöntem ve süreçleri içeren 4 madde ile ölçülmüştür. İnovasyon performansını patent sayısı, yeni ürün sayısı ya da yeni projeler veya fırsatlara yönelik finansal yatırımlar şeklinde ölçen araştırmalar olsa bile (örn., Adams vd., 2006), yenilik içeren çıktıların hem mutlak sayısal hem de zaman içerisinde değişimleri içeren çok maddeli bir ölçek ile değerlendirilmesinin daha güvenilir sonuçlar üreteceği düşünülmektedir (Wei vd., 2014; Kamaşak vd., 2019). Ayrıca inovasyon performansını sadece ürüne değil hizmet ve süreçlere ait yenilikler de etkilemektedir. Bu nedenle performansın zaman içerisindeki başarı ile ilişkilendirilmesi gerekmektedir (Kamaşak vd., 2017a).

Bu çalışmada da inovasyon performansı hem yeniliğe dayalı çıktı sayısı hem de bunların pazardaki başarısı göz önünde bulundurularak değerlendirilecektir. Demografik veri toplamaya yönelik 8 soru da dahil edildiğinde araştırmada toplam 24 soruluk nispeten kısa bir anket kullanılmıştır. Katılımcılardan her bir değişken için en uygun cevabı seçmeleri istenmiştir. İşletme yöneticilerinin değerlendirmelerini ölçebilmek için "kesinlikle katılmıyorum" ile "kesinlikle katılıyorum" aralıklarını içeren 5'li Likert ölçeğine başvurulmuştur.

Her ne kadar daha önce Türkiye bağlamında kullanılmış ve güvenilirlik ile geçerliliği test edilmiş olsa da ölçek bu araştırmada da açıklayıcı faktör analizine tabi tutulmuş ve bilgi işleme yeteneği (BiY) ölçeği BiY-1 ve Bí-2 olarak iki faktör altında toplanmıştır. Cronbach alfa değerleri BiY-1 için 0,885, BiY-2 için 0,866, inovasyon performansı için ise 0,809 olarak hesaplanmıştır. Bu anlamda ölçeklerin yüksek güvenilirlik katsayılarına sahip olduğu söylenebilir. Ayrıca değişkenler arası korelasyon katsayıları ile değişkenlerin varyans enflasyon faktörleri (VIF) hesaplandığında değişkenler arası korelasyon değerlerinin tümü 0,700, VIF skorlarının ise 3,3 altında oluştuğu görülmüştür (Hair vd., 2009). Bu açılardan modelde çoklu doğrusal bağlantı sorununa da rastlanmamış ve analizlere devam edilmiştir. Hipotezi test etmek için çoklu regresyon yöntemine başvurulmuştur. Toplanan veriler SPSS 20 paket programı ile istatistiki analize tabi tutulmuştur.

\section{ANALIZLER VE BULGULAR}

$\mathrm{Bu}$ araştırmada çoklu regresyon metodu vasıtası ile Ar-Ge merkezlerinde kullanılan bilgi işleme yetenekleri ile işletmelerin inovasyon performansı arasındaki ilişki incelenmiştir. Faktör analizi ile ortaya çıkan iki boyuttan, BiY-1 bilginin yaratma, aktarma ve entegrasyon süreçlerini ifade ederken, BiY-2 sadece bilginin uygulanması sürecini içermektedir. Bu doğrultuda, analize her iki bilgi işleme boyutu dahil edilerek devam edilmiştir. Tablo 2'de görüldügü üzere gerek BiY-1 gerekse BiY-2 boyutları ile inovasyon performansı arasında pozitif ve anlamlı bir ilişki mevcuttur.

Tablo 2: Regresyon Analizi Bulguları

\begin{tabular}{|c|c|c|c|c|c|c|}
\hline Model & $\begin{array}{c}\text { Standardize } \\
\text { Olmayan Katsayı } \\
\text { B }\end{array}$ & $\begin{array}{c}\text { Standart } \\
\text { Hata }\end{array}$ & $\begin{array}{c}\text { Standardize } \\
\text { Beta }(\beta)\end{array}$ & t değeri & $\mathbf{R}^{2}$ & Düzeltilmiş $\mathbf{R}^{2}$ \\
\hline (Sabit) & 2.765 & 0.627 & & $4.410^{* * *}$ & & \\
\hline BiY-1 & 0.347 & 0.090 & 0.331 & $3.854 * * *$ & & \\
\hline Bì-2 & 0.431 & 0.107 & 0.360 & $4.031 * * *$ & & \\
\hline Model Özeti & & & & & 0.547 & 0.539 \\
\hline
\end{tabular}

Bağımlı Değişken: İnovasyon Performansı

$* * * 0.001$ düzeyinde anlamlılık

Bilginin yaratma, aktarma ve entegrasyon süreçlerini ifade eden BiY-1 $(\beta=0.331, p<0.001)$ ve bilginin uygulama süreçlerini içeren BiY-2 $(\beta=0.360, p<0.001)$ ile inovasyon performansı arasında pozitif bir ilişki bulunmaktadır. Ayrıca, inovasyon performansındaki değişimin $\% 53,9^{\prime}$ u (Düzeltilmiş $R^{2}=0,539$ ) bilgi işleme yetenekleri tarafından açıklanmaktadır. Bu sonuçlara göre $\mathrm{H} 1$ hipotezi kabul edilmiştir.

\section{SONUÇ VE DEĞERLENDIRMELER}

Araştırma sonuçları Ar-Ge merkezine sahip işletmelerin bilgi işleme yeteneklerini etkin kullanarak inovasyon performanslarını arttırabildiklerini ortaya koymaktadır. Bu bulguların nasıl ortaya çıktığına dönük olası açıklamalar şu şekilde olabilir; etkin bilgi işleme yeteneği, insan kaynağı, örgütsel yapı ve kültür ve bilgi sermayesi arasındaki karşıııkı etkileşime bağlıdır (Kamaşak, 2012; Kamaşak ve Yücelen, 2010). Bireysel düzeydeki bilgiyi işlemek için ekip üyeleri bilgisini paylaşmalı ve yöneticiler bilginin ekip tarafından özümsenebilmesine destek olmalıdır. Yöneticilerin inovasyon üzerinde doğrudan etkisi olduğu için örgütsel öğrenmeyi kolaylaştıran faktörlere dikkat etmeleri gerekmektedir (Bulutlar ve Kamaşak, 2008; Kamaşak, 2008). Yöneticiler, ekibin önceliklere göre hazırlanabilmesi için yeni proje başlangıçlarında hedefleri haritalayabilir ve hizalayabilirler (Kamaşak vd., 2017b). Bilgi işleme yeteneğinin tüm süreçleri bireysel, grup ya da organizasyonel düzeylerde sürdürülebilir uygulamalar yaratmak için değiştirilebilmelidir. Bu açıdan düşünüldüğünde esnek organizasyonel yapılanmaların önemi bir kez daha ortaya 
çıkmaktadır. Türk şirketlerinin bilgi yeteneklerinin etkinliğini arttırmaya yönelik bir çalışmada (Zaim, 2010) başarılı bilgi yönetimi için gerekli olan altyapı unsurlarının liderlik, insan sermayesi, teknoloji, kurum kültürü ve organizasyon yapısı olduğu ortaya konulmuştur. Bu sonuçlar ışığında şirketler, nitelikli insan sermayelerini geliştirmeye özen göstermelidirler.

Benzer bir çalışmada Donate ve de Pablo (2015), bilgiyi etkin olarak işleyebilmek için bilgi odaklı liderlik davranışı, zorlayıcı motivasyon ve iletişimin gerekli olduğunu ifade etmektedir. Bilgi odaklı liderlik türü, ekip üyelerini Ar-Ge desteği yoluyla bilgi üretiminin kuruluşların hayatta kalması ve gelişmesi için temel koşul olduğuna inandırabilmektedir. Bu doğrultuda, Jansen ve arkadaşları (2009) dönüşümcü ve etkileşimci liderlik tarzlarının bilgi işlemeye katkısına işaret etmektedir. Bilgi yaratmanın yeni bağlamlar, yeni bakış açıları ve dünya görüşleri edinme ve geçmiş öğretilerin dayattığı kısıtlamalardan kurtulma sayesinde ortaya çıkabildiği ve yaratıcılığın bireysel sınırların ötesine geçen sürekli bir gelişim süreci içerdiği unutulmamalıdır.

Bilgi işleme yeteneklerine ait süreçlerin iki aşama ile temsil edildiği Türkiye bağlamında işletmeler bilginin edinilmesi, paylaşılması ve özümsenmesini tek bir süreç olarak birleştirirken uygulamayı ayrı bir süreç olarak değerlendirmektedirler. Bu bir yandan bilgi işleme süreçlerini hızlandırmakta ise de bazı süreçlerin (örn. özümseme) kendi özgün yapılanmalarını göz ardı edebilmekte ve bu da sürecin sosfistike ve daha yaratıcı çıktılar üretebilmesine olumsuz katkı yapabilmektedir. Bu doğrultuda işletmelerin bilgi işleme yetenek süreçlerini geliştirmeleri önerilebilir. Dolayısı ile araştırmaya iştirak eden firmaların inovasyon performanslarını üst düzeye çıkarabilmelerinin kolay ve verimli bilgi edinme, aktarma ve uygulamayı kolaylaştıran sağlam bilgi sistemlerine bağlı olduğu hatırlatılmalıdır.

Günümüzde çalışan X kuşağının büyük kısmı emekli olmaktadır. Şirket çalışanlarının çoğunluğu Y ve Z kuşağının üyeleridir. Dijital dünyanın içine doğan bu nesiller, iş hayatının dinamiklerini şekillendirmekte ve yönetim kademelerinde ilerlemektedirler. İş hayatındaki en önemli değerleri sosyal sorumluluk, özgüven, hedef odaklılık ve farklılıklara saygı olan bu kuşakların işyerinde eğlence, esnek çalışma programları ve kıyafetler ve işyerinde destekleyici tutumlar (takdir ve geri bildirim) gibi beklentileri vardır (Tulgan ve Martin, 2001). Ar-Ge merkezlerinin de bu gereksinimler doğrultusunda daha esnek çalışma olanakları sunan yeni stratejiler geliştirmesi beklenmektedir.

Her araştırma gibi bu araştırmanın da bazı kısıtları mevcuttur. Illk kısıt veri toplama sürecinde oluşmuştur. Veri toplama amacı ile iletişime geçilen birçok potansiyel işletme, gizliliği sağlanmış olmasına rağmen araştırmaya katılma konusunda isteksiz davranmıştır. Bu nedenle araştırmaya katılan işletme sayısı sınırı kalmıştır. İkincisi, "bakanlık tarafından akredite edilmiş ArGe merkezi" olmak kriteri çalışma örneklemi için gerekli koşul olmuştur. Her ne kadar çeşitli büyüklük ve sektörlerden heterojen bir işletme grubu ile çalışılmış olsa da bulguların tüm ülke işletmelerine genelleştirilmesi mümkün değildir. Araştırma sonuçlarının genellenebilirliğini artırmak için farklı çalışmaların tekrarlanması gerekmektedir. illeriki çalışmalarda liderlik tarzı, kültür, organizasyonel iklim ve altyapı gibi değişkenlerin gerek bilgi işleme yetenekleri üzerinden gerekse direkt etki ile inovasyon performansını nasıl etkileyeceği araştııılabilir.

\section{KAYNAKÇA}

Acharya, C., Ojha, D., Gokhale, R., Patel, P.C., (2022). Managing information for innovation using knowledge integration capability: The role of boundary spanning objects. International Journal of Information Management, https://doi.org/10.1016/i.ijinfomgt.2021.102438.

Adams, R., Bessant, J., Phelps, R., (2006). Innovation management measurement: A review. International Journal of Management Reviews, $8(1), 21-47$.

Alavi, M., Leidner, D.E., (2001). Knowledge management and knowledge management systems: Conceptual foundations and research issues. MIS Quarterly, 25(1), 107-136.

Berchicci, L., (2013). Towards an open R\&D system: Internal R\&D investment, external knowledge acquisition and innovative performance. Research Policy, 42(1), 117-127.

Braojos, J., Benitez, J., Llorens, J., Ruiz, L., (2020). Impact of IT integration on the firm's knowledge absorption and desorption. Information Management, 57(7), 1-17.

Bulutlar, F., Kamaşak, R., (2008). The relationship between organizational communication and job satisfaction: An empirical study on the blue collar workers. Dumlupınar University Journal of Social Sciences, 22(4), 129-142.

Cebeci, C., Kamaşak, R., (2021). Sosyal zekâ ve içsel motivasyonun Ar-Ge performansına etkisi: Ar-Ge merkezleri çalışanları üzerine bir araştırma. İşletme Araştırmaları Dergisi, 13(1), 47-66.

Chen, Y., Luo, H., Chen, J., Guo, Y., (2022). Building data-driven dynamic capabilities to arrest knowledge hiding: A knowledge management perspective. Journal of Business Research, 139(C), 1138-1154.

Donate, M.J., de Pablo, S.J.D., (2015). The role of knowledge-oriented leadership in knowledge management practices and innovation. Journal of Business Research, 68(2), 360-370.

Easterby-Smith, M., Araujo, L., Burgoyne, J., (1999). Organizational learning and the learning organization: Developments in theory and practice. SAGE, London, UK. 
Easterby-Smith, M., Lyles, M.A., (eds.), (2003). The Blackwell handbook of organizational learning and knowledge management. Blackwell, Malden, MA.

Ermine, J.-L., (2018). Knowledge management. John Wiley and Sons, Hoboken, NJ.

Gibson, C.B., Birkinshaw, J., (2004). The antecedents, consequences, and mediating role of organizational ambidexterity. Academy of Management Journal, 47(2), 209-226.

Gold, A.H., Malhotra, A., Segars, A.H., (2001). Knowledge management: An organizational capabilities perspective. Journal of Management Information Systems, 18(1), 185-214.

Gonzalez, R.V.D., (2021). Innovative performance of project teams: The role of organizational structure and knowledge-based dynamic capability. Journal of Knowledge Management, https://doi.org/10.1108/JKM-03-2021-0259.

Grant, R.M., (1996). Prospering in dynamically-competitive environments: Organizational capability as knowledge integration. Organization Science, 7(4), 375-387.

Hair, J.F., Black, W.C., Babin, B.J., Anderson, R.E., (2009). Multivariate data analysis (7th ed.). Englewood Cliff, NJ: Prentice Hall.

Henttonen, K., Lehtimäki, H., (2017). Open innovation in SMEs: Collaboration modes and strategies for commercialization in technologyintensive companies in forestry industry. European Journal of Innovation Management, 20(2), 329-347.

Jansen, J.J.P., Vera, D., Crossan, M., (2009). Strategic leadership for exploration and exploitation: The moderating role of environmental dynamism. The Leadership Quarterly, 20(1), 5-18.

Jantunen, A., (2005). Knowledge-processing capabilities and innovative performance: An empirical study. European Journal of Innovation Management, 8(3), 336-349.

Joshi, A., Benitez, J., Huygh, T., Ruiz, L., De Haes, S., (2021). Impact of IT governance process capability on business performance: Theory and empirical evidence, Decision Support Systems, https://doi.org/10.1016/j.dss.2021.113668.

Kamaşak, R., (2011). Firm specific versus industry structure factors in explaining performance variation: Empirical evidence from Turkey. Management Research Review, 34(10), 1125-1146.

Kamaşak, R., Yavuz, M., Altuntas, G., (2016a). Is the relationship between innovation performance and knowledge management contingent on environmental dynamism and learning capability? Evidence from a high turbulent market. Business Research, 9(2), $229-253$.

Kamaşak, R., Yavuz, M., Karagulle, O., Ağca, T., (2016b). Importance of strategic flexibility on the knowledge and innovation relationship: An emerging market study. International Conference on Management and Information Technology, 11 December, Istanbul, Turkey, (Elsevier Procedia - Social and Behavioral Sciences, Vol. 229C, pp. 126-132).

Kamaşak, R., Yozgat, U., Yavuz, M., (2017a). Knowledge process capabilities and innovation: Testing the moderating effects of environmental dynamism and strategic flexibility. Knowledge Management Research \& Practice, 15(3), 356-368.

Kamaşak, R., Yavuz, M., Özturk, T.Y., (2017b). Reducing risk through strategic flexibility and implementation leadership in high-velocity markets. In: Hacioglu, U., Dincer, H. and Alayoglu, N. (eds.), Global Business Strategies in Crisis: Strategic Thinking and Development (pp. 273286). Springer, Cham, Switzerland.

Kamaşak, R., (2008). The impact of communication climate and job satisfaction in employees' external prestige perceptions. Yönetim ve Ekonomi, 15(2), 133-144.

Kamaşak, R., (2012). Knowledge management practice assessment and the relationship between knowledge management practices and organizational strategy development: Empirical evidence from Turkey. In: Hou, H-T. (ed.), New Research on Knowledge Management Applications and Lessons Learned (pp. 35-46). InTech Publications, Rijeka, Croatia.

Kamaşak, R., (2013). Resource-based view (RBV) in all its aspects. Scholars' Press Publishing, Halberg, Germany.

Kamaşak, R., (2014). Another attempt to look inside the 'black box' of performance creation: A case study approach. International Journal of Business and Social Research, 4(7), 1-16.

Kamaşak, R., (2015a). Creation of firm performance through resource orchestration: The case of Ülker. Competitiveness Review, 25(2), 179204.

Kamaşak, R. (2015b). Determinants of innovation performance: A resource-based study. World Conference on Technology, Innovation and Entrepreneurship, 28-30 May, Istanbul, Turkey, (Elsevier Procedia - Social and Behavioral Sciences, Vol. 195C, pp. 1330-1337).

Kamaşak, R., (2017). The contribution of tangible and intangible resources, and capabilities to a firm's profitability and market performance. European Journal of Management and Business Economics, 26(2), 252-275.

Kamaşak, R., Bulutlar, F., (2010). The influence of knowledge sharing on innovation. European Business Review, $22(3), 306-317$.

Kamaşak, R., Cansever, C., (2019). The predictors of sustained competitive advantage: A study of the Turkish leasing industry. 21st Budapest Internatıonal Conference on Law, Business, Gender and Interdisciplinary Studies, 22-24 July, Budapest, Hungary, (Proceedings, pp. 1-5).

Kamaşak, R., James, S.R., Yavuz, M., (2019). The interplay of corporate social responsibility and corporate political activity in emerging markets: The role of strategic flexibility in nonmarket strategies. Business Ethics: A European Review, 28(3), 305-320. 
Kamaşak, R., Yavuz, M., (2016). The use of business processes as a source of competitive advantage: Evidence from a high velocity market. Marmara Journal of Pure and Applied Sciences, 28(S1), 28-33.

Kamaşak, R., Yozgat, U., (2013). Industrial factors, unique resources and performance relationship: A study on service and manufacturing firms. Journal of Akdeniz University Faculty of Economics and Administrative Sciences, 27(2), 114-136.

Kamaşak, R., Yücelen, M., (2010). The relationship between knowledge assets and organizational strategy development. International Journal of Business and Management Studies, 2(2), 65-72.

Kang, K.H., Kang, J., (2014). Do External knowledge sourcing modes matter for service innovation? Empirical evidence from South Korean service firms. Journal of Product Innovation Management, 31(1), 176-191.

Kogut, B., (200). The network as knowledge: Generative rules and the emergence of structure. Strategic Management Journal, 21(3), 405425.

Kraaijenbrink, J., (2012). Integrating knowledge and knowledge processes: A critical incident study of product development projects. Journal of Product Innovation Management, 29(6), 1082-1096.

Lee, J.-S., Park, J.-H., Bae, Z.-T., (2017). The effects of licensing-in on innovative performance in different technological regimes. Research Policy, 46(2), 485-496.

Long, D.D., (1997). Building the knowledge-based organization: How culture drives knowledge behaviors. Ernst \& Young Center for Business Innovation, Working Paper, Boston 1.

Marsh, S.J., Stock, G.N., (2006). Creating dynamic capability: The role of intertemporal integration, knowledge retention, and interpretation. Journal of Product Innovation Management, 23(5), 422-436.

McDowell, W.C., Peake, W.O., Coder, L., Harris, M.L., (2018). Building small firm performance through intellectual capital development: Exploring innovation as the "black box". Journal of Business Research, 88(C), 321-327.

Mol, M., Birkinshaw, J.M., (2014). The role of external involvement in the creation of management innovations. Organization Studies, 35(9), $1287-1312$

Monteiro, F., Birkinshaw, J., (2017). The external knowledge sourcing process in multinational corporations. Strategic Management Journal, 38(2), 342-362.

Mostafiz, M.I., Hughes, M., Sambasivan, M., (2021). Entrepreneurial orientation, competitive advantage and strategic knowledge management capability in Malaysian family firms. Journal of Knowledge Management, https://doi.org/10.1108/JKM-09-2020-0693.

Nonaka, I., (1994). A dynamic theory of organizational knowledge creation. Organization Science, 5(1), 14-37.

Parrilli, M.D., Elola, A., (2012). The strength of science and technology drivers for SME innovation. Small Business Economics, $39(4), 897-907$.

Pınar, İ., Kamaşak, R., Bulutlar, F., (2010). The relationship between command and enforced choice strategy development processes and innovativeness. Öneri - Journal of Marmara University Institute of Social Sciences, 9(33), 11-16.

Polanyi, M., (1962). Tacit knowing: Its bearing on some problems of philosophy. Reviews of Modern Physics, 34(4), 601-616.

Polanyi, M., (1966). The logic of tacit inference. Philosophy, 41(1), 1-18.

Polanyi, M., Prosch, H., (1975). Meaning. University of Chicago Press, Chicago, IL.

Sanayi Bakanlığı, (2021). Ar-Ge merkezleri, https://www.sanayi.gov.tr/istatistikler/istatistiki-bilgiler/mi0203011502.

Savino, T., Petruzzelli, M. A., Albino, V., (2017). Search and recombination process to innovate: A review of the empirical evidence and a research agenda. International Journal of Management Reviews, 19(1), 54-75.

Tanriverdi, H., (2005). Information technology relatedness, knowledge management capability, and performance of multibusiness firms. MIS Quarterly 29(2), 311-334.

Teece, D.J., (1998). Capturing value from knowledge assets: The new economy, markets for know-how, and intangible assets. California Management Review, 40(3), 55-79.

Teece, D.J., (2018). Business models and dynamic capabilities, Long Range Planning, 51(1), 40-49.

Teece, D.J., Pisano, G., Shuen, A., (1997). Dynamic capabilities and strategic management. Strategic Management Journal, 18(7), $509-533$.

Tulgan, B., Martin, C.A., (2001). Managing generation Y: Global citizens born in the late seventies and early eighties. HRD Press, Amherst, Mass.

Turulja, L., Bajgoric, N., (2018). Knowledge acquisition, knowledge application, and innovation towards the ability to adapt to change. International Journal of Knowledge Management, 14(2), 1-15.

Wei, Z., Yi, Y., Guo, H., (2014). Organisational learning, ambidexterity, strategic flexibility, and new product development. Journal of Product Innovation Management, 31(4), 832-847. 
$\mathrm{Wu}$ I.-L., Chen, J.-L., (2014). Knowledge management driven firm performance: the roles of business process capabilities and organizational learning. Journal of Knowledge Management, 18(6), 1141-1164.

Yayavaram, S., Chen. W.R., (2015). Changes in firm knowledge couplings and firm innovation performance: The moderating role of technological complexity. Strategic Management Journal, 36(3), 377-396.

Zahra, S.A., Neubaum, D.O., Larraneta, B., (2007). Knowledge sharing and technological capabilities: the moderating role of family involvement. Journal of Business Research, 60(10), 1070-1079.

Zaim, H., (2010). Knowledge management infrastructure and knowledge management performance: A field study in Turkey. Sosyal Siyaset Konferansları Dergisi, 59(1), 51-67.

Zander, U., Kogut, B., (1995). Knowledge and the speed of the transfer and imitation of organizational capabilities: An empirical test. Organization Science, 6(1), 76-92.

Zollo, M., Winter, S.G., (2002). Deliberate learning and the evolution of dynamic capabilities. Organization Science, 13(3), 339-351.

Zott, C., (2003). Dynamic capabilities and the emergence of intraindustry differential firm performance: Insights from a simulation study. Strategic Management Journal, 24(2), 97-125. 